\title{
RELATIONSHIP BETWEEN SAR/SENTINEL-1 POLARIMETRIC AND INTERFEROMETRIC DATA WITH BIOPHYSICAL PARAMETERS OF AGRICULTURAL CROPS
}

\author{
Victor Hugo Rohden Prudente ${ }^{1, *}$, Lucas Volochen Oldoni ${ }^{1}$, Denis Corte Vieira ${ }^{1}$, Carlos Eduardo Vizzotto Cattani ${ }^{2}$ and \\ Ieda Del'Arco Sanches ${ }^{1}$

\begin{abstract}
${ }^{1}$ National Institute for Space Research (INPE), Av. dos Astronautas, 1758, Jardim da Granja, 12227-010 - São José dos Campos, SP, Brazil \{ victor.prudente, lucas.oldoni, denis.vieira, ieda.sanches\}@inpe.br

${ }^{2}$ Western Paraná State University, Postgraduate Program in Agricultural Engineering, R. Universitária, 2069 - Jardim Universitário. Cascavel - PR, carlos.cattani@unioeste.br
\end{abstract}

Commission III, WG III/10

KEY WORDS: Microwave, LAI, Height, soybean, wheat, coherence, backscatter, polarization.

\begin{abstract}
:
The use of SAR (Synthetic Aperture Radar) data in agricultural applications has not yet been adequately explored, due to the complexity of the processing required, the lower diversity and availability of SAR data, and the difficulty in interpreting this data. The interactions between microwave energy and vegetation are influenced by factors related to plant structure, dielectric properties of the canopy, planting density and line orientation, and the angle of incidence and polarization of the wave. These differences between the recorded phases are used in data analysis techniques such as polarimetry and interferometry. Thus, the objective of this research is to analyse the relationships between the biophysical attributes of two agricultural crops (soybean and wheat) and the polarimetric and interferometric parameters of the SAR/Sentinel-1 data. The backscatter coefficients sigma and gamma in the VV polarization have inversely direct relation with the height of the crops, that is, as cultures grow, the interaction of energy in this polarization increases and the return signal decreases. For the cross polarization $\mathrm{VH}$, the behaviour is the opposite, the larger the canopy height, the greater the interaction of vertical polarization and the greater the return on horizontal polarization. The interferometric coherence had small values, characterising a temporal decorrelation between the image pairs, due the canopy development. This preliminary study serves as a basis for future research with SAR/Sentinel-1 data focused on crops.
\end{abstract}

\section{INTRODUCTION}

Remote sensing provides information of large areas and/or of difficult access, in almost real time, being a powerful tool for agricultural mapping and monitoring (Veloso et al., 2017). Microwave sensors, such as the Synthetic Aperture Radar (SAR) collect data in almost all-weather conditions, independently of lighting conditions and are poorly affected by atmospheric and cloud conditions (Liu et al., 2013; Parihar et al., 2014). For this reason, it is possible to obtain dense temporal series of SAR data, even in areas with large cloud cover, such as tropical regions.

However, there are many different factors that influences the interaction among plant canopies and microwave energy. These proprieties are influenced by the proprieties of the radar system itself, polarization and frequency and/or by canopy properties, like dielectric constant, size, orientation, incidence angle, etc. (Liu et al., 2013; Steele-Dunne et al., 2017). These canopy properties impact the intensity of SAR scattering, type of scattering and phase characteristics. They are crop specific and varies as crop phenology changes, thus, there is significant potential for the use of SAR in agricultural applications, like classification, crop monitoring, and soil/vegetation moisture monitoring (Steele-Dunne et al., 2017).

Each polarization is more sensitive to certain characteristics of canopies. The HH polarization is more sensitive to surface scattering. Cross-polarization, $\mathrm{VH}$ and $\mathrm{HV}$, is more sensitive to volume dispersion, and VV is a combination of the two (Veloso et al., 2017).

\footnotetext{
* Corresponding author
}

In this context, the launch of Sentinel-1A and -1B SAR satellites it's a new opportunity to investigate agricultural monitoring methods based on dense SAR time series (Tamm et al., 2016). SAR polarimetric, such as Sentinel-1, obtain scatter echoes from multiple polarimetric channels and thus provide information richer than single polarization, which can help improve segmentation, classification, target detection, and pattern recognition. The polarimetric decomposition of targets is a method that represents the scattering of targets by several basic dispersion mechanisms ( $\mathrm{Ji}$ and $\mathrm{Wu}, 2015)$.

From the Cloude-Pottier decomposition, it is possible to obtain the polarimetric attributes of entropy $(H)$ and angle alpha $(\alpha)$. Entropy is the randomness of the scattering, which ranges from 0 (coherent) to 1 (purely random). The alpha angle identifies the type of scattering, which varies from irregular $\left(0^{\circ}\right.$ to $\left.45^{\circ}\right)$ and double $\left(45^{\circ}\right.$ to $\left.90^{\circ}\right)$ (Cloude and Pettier, 1996).

Interferometry is the process that analyses the correlation between two images of the same area in different dates, where low coherence reflects that the areas present temporal decorrelation, having a change in the structure of the place. The interferogram is generated by the complex conjugate multiplication of two coregistered SAR images, that can be acquired simultaneously (also known as single-pass configuration) and/or a repeat-pass configuration at different times (Erten et al., 2016). To avoid temporal decorrelation in this approach, images should be acquired with short time interval as possible in order to reduce the chance of changes in the scene. Moreover, the spatial baseline, distance between the positions of the radar sensors when they acquire the images, should be as short as possible (López-Martínez and Lopez-Sanchez, 2017). 
The coherence is a correlation coefficient that explains the noise present in a SAR interferogram and is associate with small changes in the surface occurring during the time interval between two SAR acquisitions (Mohammadimanesh et al., 2018; Parihar et al., 2014; Srivastava et al., 2006). This coefficient ranges from 0 to 1 , where a large coherence (near 1) coefficient indicates that the pixel change is small, whereas a small coherence coefficient (near 0 ) indicates that the change is large (Zhou et al., 2017). This temporal decorrelation increases in agricultural land, resulting from the process of vegetation growth. Therefore, interferometric coherence is a parameter that provides valuable information, which is completely different from the SAR backscatter information. In this sense, interferometric coherence values are associated with canopy height values (Parihar et al., 2014; Tamm et al., 2016; Zhou et al., 2017).

Thus, the objective of this research is to demonstrate the relationships between the biophysical attributes of two agricultural crops (soybean and wheat) and the polarimetric and interferometric parameters of the SAR/Sentinel-1 data.

\section{MATERIAL AND METHODS}

\subsection{Field data}

We monitored 24 points at a commercial agricultural area

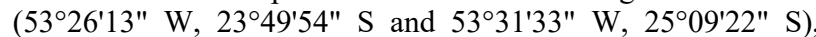
locate in the municipality of Cascavel - Parana State - Brazil. In that area two different crops were accompanied, the soybean in the summer harvest of 2015/2016 and the wheat in the winter harvest of 2016.

Soybean was sown in 2015 , October $6-7^{\text {th }}$, with a row space of $0,45 \mathrm{~m}$. Soybean harvest occurred in 2016 , February $03-10^{\text {th }}$. Wheat crop was sown in 2016 , May $16^{\text {th }}$, with $0,20 \mathrm{~m}$ of row space. The wheat harvest was in 2016 , October $17^{\text {th }}$. The biophysical parameters of Leaf Area Index (LAI) and height of plants were measured with a LAI2200C and a metal tape measure, respectively, in different Days After Sowing (DAS) (Table 1).

\begin{tabular}{cccc}
\hline \multicolumn{2}{c}{ Soybean } & \multicolumn{2}{l}{ Wheat } \\
\hline DAS & Date & DAS & Date \\
\hline 034 & $2015 / 11 / 10$ & 017 & $2016 / 06 / 02$ \\
045 & $2015 / 11 / 21$ & 032 & $2016 / 06 / 17$ \\
071 & $2015 / 12 / 17$ & 047 & $2016 / 07 / 02$ \\
076 & $2015 / 12 / 22$ & 064 & $2016 / 07 / 19$ \\
110 & $2016 / 01 / 25$ & 080 & $2016 / 08 / 04$ \\
& & 101 & $2016 / 08 / 25$ \\
& & 114 & $2016 / 09 / 07$ \\
& & 128 & $2016 / 09 / 21$ \\
\hline
\end{tabular}

Table 1. Dates of height and LAI measurements.

The LAI-2200C sensor (LI-COR, Lincoln, Nebraska, USA) does not require direct physical contact with the target, and the reading is based on radiation transmitted through the leaves (Zheng and Moskal, 2009). The readings with the LAI-2200C were performed $0.2 \mathrm{~m}$ above the canopy and at the soil level, transverse to the planting rows (between the rows). The number of repetitions of the readings ranged from 3 to 4 , according to the Apparent Clumping Factor (ACF). For ACF values greater than $90 \%$, three sets of repetitions were performed, with one reading above and four readings below the canopy, with a $270^{\circ}$ view cap. For ACF values less than $90 \%$, the collections were performed with four sets of repetitions, with two sets of readings facing the rows and the other two sets toward the rows between the plants, using a view cap with a $45^{\circ}$ aperture. Correction of the readings (Factor " $\mathrm{K}$ ") was also carried out due to solar influence (LI-COR, 2014).

To obtain measurements of plant height in each sampling point, height measurements were taken of 3 random plants. Plant height was measured from the soil to the apex of the plant.

\subsection{SAR data}

The SAR Sentinel-1 images were acquired in IW (Interferometric Wide swath) mode, SLC (Single Look Complex) and comprise the development period of the crops in each harvest were used (Table 2). The images were obtained through the Sentinels Scientific Data Hub, and they were preprocessed using the Sentinel Application Platform-SNAP applications (ESA, 2013).

\begin{tabular}{cccc}
\hline \multicolumn{2}{c}{ Soybean } & \multicolumn{2}{l}{ Wheat } \\
\hline DAS & Date & DAS & Date \\
\hline & & -005 & $2016-05-10$ \\
& & 000 & $2016-05-15$ \\
-025 & $2015-09-13$ & 018 & $2016-06-03$ \\
-013 & $2015-09-25$ & 023 & $2016-06-08$ \\
000 & $2015-10-07$ & 066 & $2016-07-21$ \\
005 & $2015-10-12$ & 071 & $2016-07-26$ \\
012 & $2015-10-19$ & 090 & $2016-08-14$ \\
024 & $2015-10-31$ & 095 & $2016-08-19$ \\
029 & $2015-11-05$ & 119 & $2016-09-12$ \\
048 & $2015-11-24$ & 137 & $2016-09-30$ \\
096 & $2016-01-11$ & 144 & $2016-10-07$ \\
113 & $2016-01-28$ & 156 & $2016-10-19$ \\
120 & $2016-02-04$ & 161 & $2016-10-24$ \\
& & 168 & $2016-10-31$ \\
\hline
\end{tabular}

Table 2. Dates of SAR images.

\subsection{Polarimetric}

We obtained the sigma and gamma nought backscattering coefficients calculation (sigma 0 and gamma 0 ), in the $\mathrm{VV}$ and VH polarizations. Also, was obtained the Entropy and Alpha angle polarimetric process. Initially, the TOPSAR Split was applied to select only the bursts that covered the study area. Subsequently the TOPSAR Deburst was performed. Then the processing was divided into two parts, one to obtaining the backscatter coefficients for the $\mathrm{VV}$ and $\mathrm{VH}$ polarizations, and the other to obtain the polarimetric entropy and alpha angle attributes. 
In order to obtain the backscatter coefficients, after the TOPSAR Deburst, the orbit correction (Apply Orbit File) and the thermal noise removal (Thermal Noise Removed) were performed. Then the radiometric calibration was performed to obtain the sigma and gamma in the $\mathrm{VV}$ and $\mathrm{VH}$ polarizations, using the SNAP "Calibration" module. In the sequence, the procedure of resampling through the spatial average, named Multilook with a window size of $4 \times 1$ pixels, was performed. The spacing between pixels being converted from 2.33 and $14.05 \mathrm{~m}$ to $14.05 \mathrm{~m}$ in the range and azimuth directions, respectively. This procedure help in Speckle noise reduction.

A Lee filter with a window size of $5 \times 5$ pixels was then applied, in order to reduce speckle noise. After filtering, the Land Doppler Terrain Correction was applied using a Shuttle Radar Topography Mission (SRTM) digital elevation model (DEM) to geocode the images. This process generated images with spatial resolution of $14.05 \mathrm{~m}$. Finally, the sigma 0 and gamma 0 coefficients were converted from the linear scale to logarithmic scale $(\mathrm{dB})$.

Entropy and alpha angle were processed through the SNAP software too. The H-Alpha polarimetric decomposition of the SAR/Sentinel-1 data was performed to obtain the entropy and alpha angle attributes.

To obtain the polarimetric attributes, after the TOPSAR Deburst the Covariance matrix [C2] was generated, which was also submitted to the $4 \times 1$ pixel Multilook resampling process and filtered with the Refined Lee filter with $5 \times 5$ pixels size window to reduce the speckle noise. Then, the H-Alpha polarimetric decomposition was performed to obtain the entropy and angle $\alpha$ attributes. Correction of the terrain was also applied using the SRTM DEM.

\subsection{Interferometric}

In the interferometric process we calculate interferometric coherence between 5 pairs of images for soybean and 4 pairs for wheat. The nearby date images, with same IW mode, were chosen for this. The dates and baseline of this imagens are showed at the Table 3 . The images process per each pair was TOPS Coregistration, Interferogram Generation, TOPS Deburst, Goldstein Phase Filtering and Terrain Correction (Parihar et al., 2014; Tamm et al., 2016; Zhou et al., 2017).

\begin{tabular}{llccc}
\hline Crop & Dates & DAS & Bperp $(\mathrm{m})$ & Days \\
\hline Soybean & $2015 / 09 / 25-10 / 07$ & $-13 / 00$ & 28.34 & 12 \\
Soybean & $2015 / 10 / 07-19$ & $00 / 12$ & 14.79 & 12 \\
Soybean & $2015 / 10 / 19-31$ & $12 / 24$ & 35.44 & 12 \\
Soybean & $2015 / 10 / 31-11 / 24$ & $24 / 48$ & 74.77 & 24 \\
Soybean & $2016 / 01 / 11-02 / 04$ & $96 / 120$ & 23.88 & 24 \\
Wheat & $2016 / 05 / 10-06 / 03$ & $-05 / 18$ & 46.74 & 24 \\
Wheat & $2016 / 07 / 21-08 / 14$ & $66 / 90$ & 93.58 & 24 \\
Wheat & $2016 / 10 / 07-19$ & $144 / 156$ & 104.01 & 12 \\
Wheat & $2016 / 10 / 19-31$ & $156 / 168$ & 46.52 & 12 \\
\hline
\end{tabular}

Table 3. SAR interferometric dates.

With the TOPS coregistration tools was selected and coregistred the bursts for each image. In this step was applied the orbit correction per each image and the resample method to coregistration was the nearest neighbourhood. After the coregister, next step was generating the Interferogram. For this, was subtracted flat-earth phase and used the coherence range windows size equal to 10 . In this step is generated the coherence images.
Following, the Debursts process was made for join the burst selected at the TOPS coregistration step. Continuing the process, we applied the Goldstein Phase filtering to remove noises presents at the phase. Adaptative filter exponent equal to 1, Fast Fourier transform (FFT) size equal a 64, windows size of 3 and coherence threshold equal to 0,2 was the parameters utilized in this part. For last, the terrain correction for all data was applied. This process is similar to the process mentioned before.

\subsection{Data analysis}

To relate the temporal behaviour of the polarimetric and interferometric data to the biophysical parameters of the crops, proximal DAS between SAR and biophysical parameters were used. Thus, for polarimetric and interferometric parameters different DAS were used for soybean and wheat (Table 4). Using R software, we performed the correlation analyses, Spearman at 5\% significance level, and simple regression models with adjusted coefficient of determination $\left(\mathrm{R}_{\text {adj }}^{2}\right)$ between biophysical parameters and SAR data.

\begin{tabular}{ccccc}
\hline & Soybean & \multicolumn{3}{c}{ Wheat } \\
\hline Polarimetry & Field & SAR & Field & SAR \\
& 034 & 029 & 017 & 018 \\
& 045 & 048 & 064 & 066 \\
& 110 & 113 & 101 & 095 \\
\hline Interferometry & 045 & $24 / 48$ & 017 & $-05 / 18$ \\
& 110 & $96 / 120$ & 080 & $66 / 90$ \\
\hline
\end{tabular}

Table 4. DAS SAR data and field for soybean and wheat.

All polarimetric and interferometric processing involve were made at the RUS virtual machine (Palazzo et al., 2018). SAR processor was made at the SNAP software. Data extract and organizations was process for the python language. Graphs and relations were performed at the software $\mathrm{R}$.

\section{RESULTS AND DISCUSSION}

The results are divided in two sections. The first section shows the biophysical and SAR behaviour. The second section present the relation between SAR and biophysical parameters.

\subsection{Soybean and wheat parameters}

In Figure 1 the crops biophysical parameters, Height and LAI, are presented. The maximum height it's near 1.0 meter, at the DAS 71 for soybean and DAS 114 for wheat. Soybean LAI reaches higher values compared to wheat LAI. 

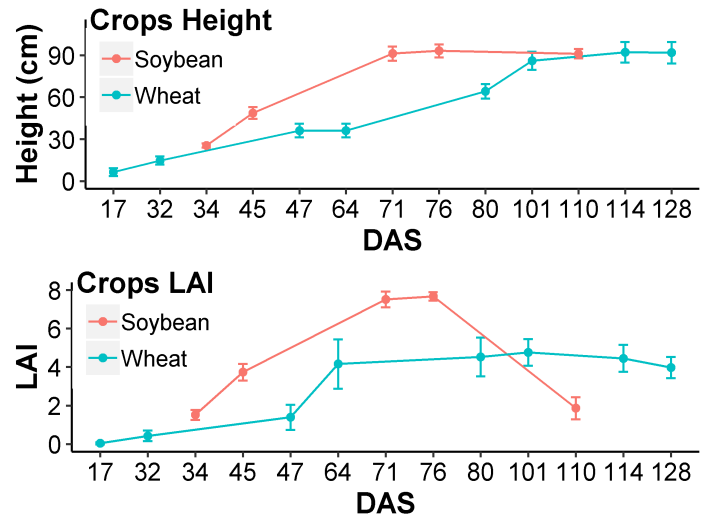

Figure 1. Mean (solid line) and standard (error bar) deviation for Height and LAI for soybean and wheat crops.

SAR polarimetric metrics for soybean are presented in Figure 2. Sigma 0 and gamma 0 have similar patterns. VV backscattering had a peak in DAS 5, then decreases at DAS 12, growing rapidly, reaching the maximum value in DAS 29 , maintaining values between $-5 \mathrm{~dB}$ and $-10 \mathrm{~dB}$ until DAS 120. In VH the pattern is like VV polarization, but the backscattering values are small, $-10 \mathrm{~dB}$ until $-21 \mathrm{~dB}$. Entropy increases in value from 0.45 , in DAS 12 , to 0.80 in DAS 120 . In other hand, the alpha angle has opposite pattern, with higher values close to $80^{\circ}$ at sowing, DAS 0, decreasing in the sequence, until $65^{\circ}$, in DAS 120.

For wheat, the SAR polarimetric patterns are showed in Figure 3. Sigma 0 and gamma 0 backscattering have similar patterns in both polarizations, with values between $-8 \mathrm{~dB}$ and $-15 \mathrm{~dB}$ for $\mathrm{VV}$ polarization and $-14 \mathrm{~dB}$ and $-20 \mathrm{~dB}$ for $\mathrm{VH}$ polarization. Entropy increases from 0.52, DAS 23, until 0.88 at DAS 95. After, decreases until 0.47 at DAS 161. Alpha angle had two cycles, one with pick at DAS 23 , with $77^{\circ}$, decreasing until $60^{\circ}$ at DAS 95, and increase again until $79^{\circ}$ at DAS 161.
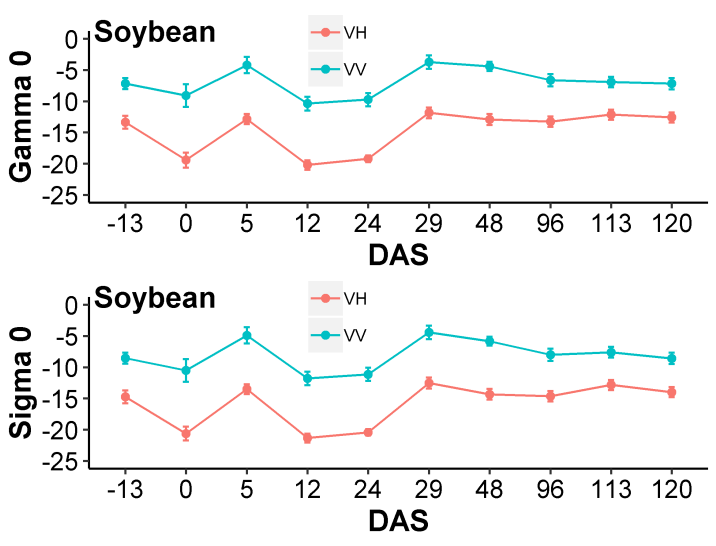
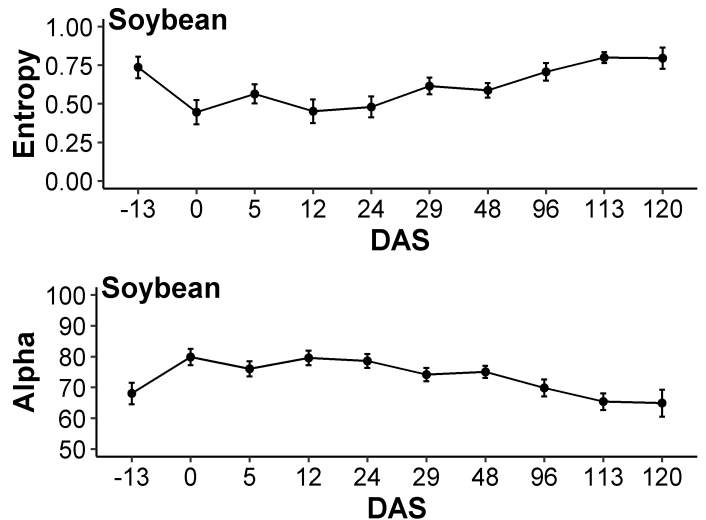

Figure 2. Mean (black line) and standard (error bar) deviation for Sigma $0(\mathrm{~dB})$, Gamma $0(\mathrm{~dB})$, Entropy and Alpha angle for soybean crop.
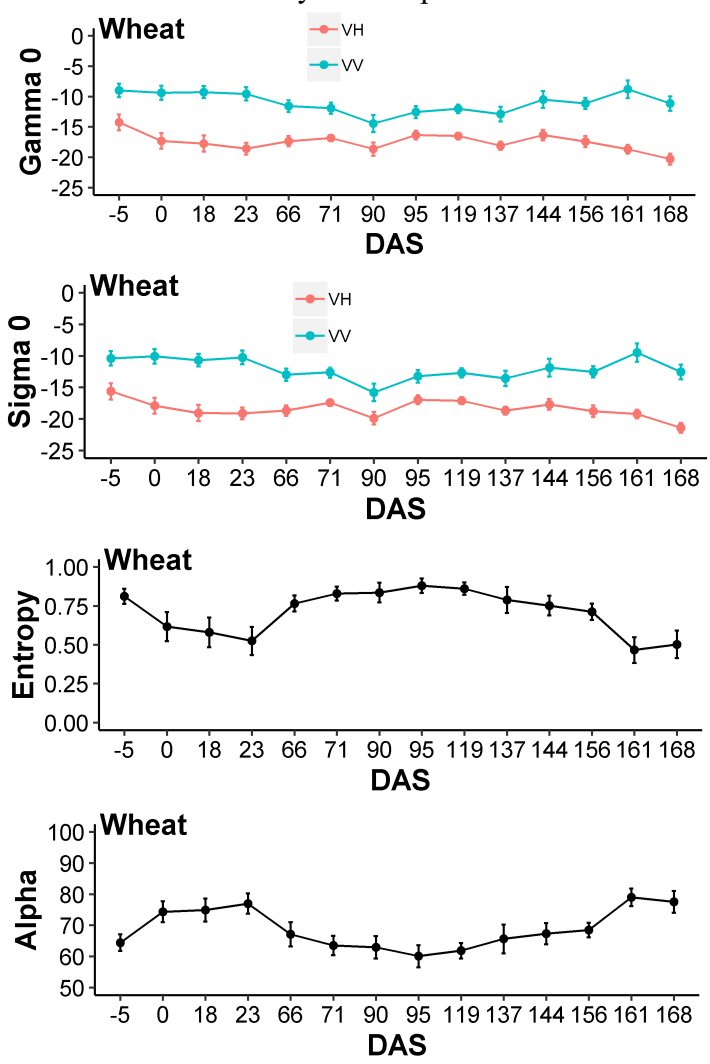

Figure 3. Mean (black line) and standard (error bar) deviation for Sigma, Gamma, Entropy and Alpha angle for wheat crop.

Zhou et al. (2017) also found small backscatter value of VH polarization compared to VV. Zhou et al. (2017) and McNairn et al. (2009) related that in the early stage of plant growth, soil play a leading role in radar backscatter. Later in the growing season, the vegetation backscattering is more pronounced as a result of increased differences in canopy structure and moisture content.

Interferometric coherence value for both crops are showed in Figure 4 . The values are small and constant in both crops cycle; with represent a high pixel change between dates. Our results of coherence were similar to Zhou et al. (2017), Parihar et al. (2014) and Tamm et al. (2016). 


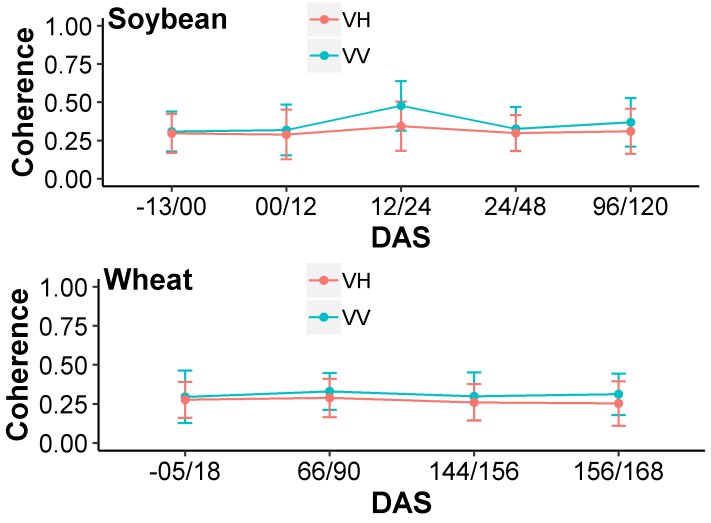

Figure 4. Mean (black line) and standard (error bar) deviation for interferometric coherence.

\subsection{Correlations between SAR and crop biophysical parameters}

Correlation between biophysical and SAR parameters are showed in Figure 5. Co-polarization VV have negative correlation with height crops and LAI wheat in sigma 0 and gamma 0 . However, for LAI soybean did not have significant correlation. In other hand, cross-polarization have positive correlation with the crop heights and LAI wheat, however, the cross-polarization have negative correlation with LAI wheat. Entropy was inversely related with LAI soybean and directly related with crops heights and LAI wheat. Alpha angle was inversely related with crops heights and LAI wheat and directly related with LAI soybean.

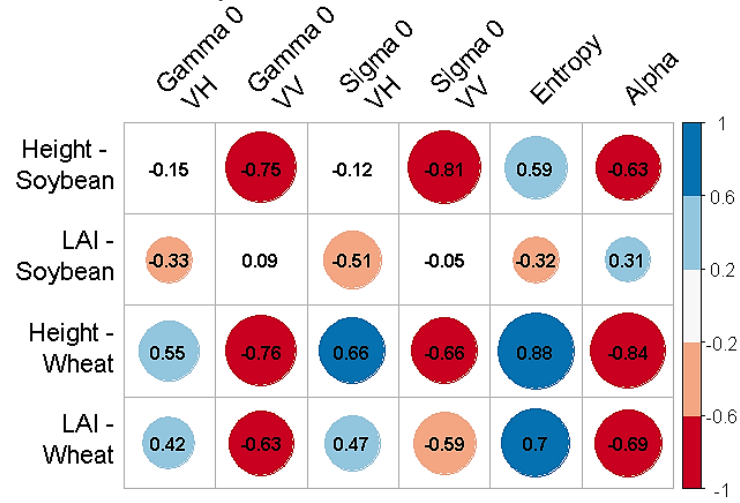

Figure 5. Correlation plot for soybean and wheat. White spaces, without circles, are insignificant at $5 \%$ of significance.

Among all biophysical and coherence parameters, just coherence at the VV polarization had positive significant correlation with wheat's height $(\mathrm{rs}=0.32)$. There was no significant correlation, at $5 \%$ of significance, between interferometric coherence and the others biophysical parameters for both crops.

Figure 6 shows the scatter plots between the height and the SAR attributes for soybean. Like was see in Figure 5, the crosspolarization backscattering sigma 0 and gamma 0 were SAR parameters with lower $\mathrm{R}_{\text {adj }}^{2}$, without tendencies. The others $\mathrm{R}_{\text {adj }}^{2}$ were greater than 0.6. Co-polarization backscattering and alpha show the relation inversely relation, that is, smaller values of height have higher values of the parameters. Only entropy showed a positive relationship, therefore, the greater the height the greater the entropy.

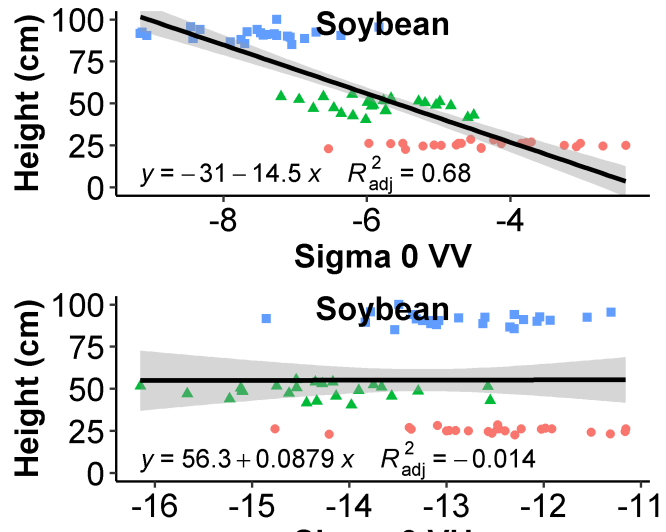

Sigma 0 VH
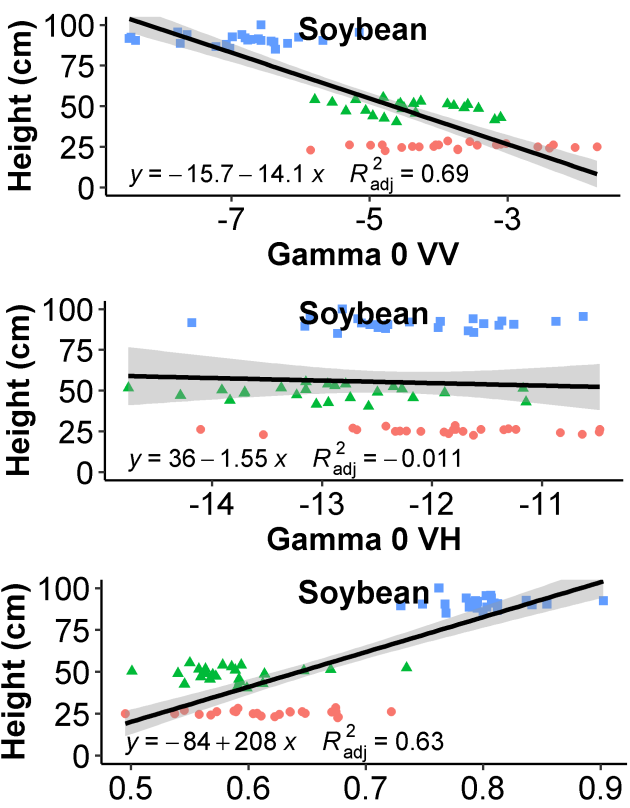

Entropy

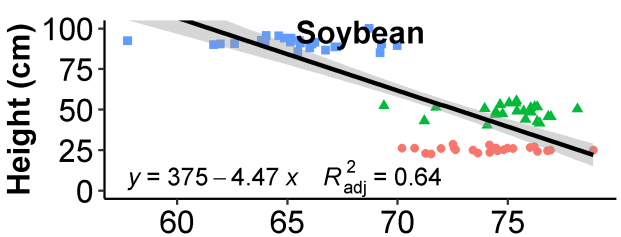

Alpha

Legend

$$
\begin{aligned}
& \text { Height }(\mathrm{cm}) \text { :DAS } 034 \\
& \text { SAR:DAS 029 } \\
& \text { Height }(\mathrm{cm}) \text { :DAS } 045 \\
& \text { SAR:DAS 048 } \\
& \text { Height (cm):DAS } 110 \\
& \text { SAR:DAS } 113
\end{aligned}
$$

Figure 6. Relationship between Height and Sigma, Gamma, Entropy and Alpha angle for soybean.

The scatter plots between height and SAR attributes for wheat (Figure 7) show directly relation among height and crosspolarizations backscattering and entropy. Moreover, there are inversely relation among wheat height and co-polarization backscattering and alpha. The differences among the relation showed in Figure 6 and 7 were the presence of relation between cross-polarization backscattering with the wheat height and the greater values of $\mathrm{R}^{2}$ adj for entropy and alpha at wheat than at soybean crop. 

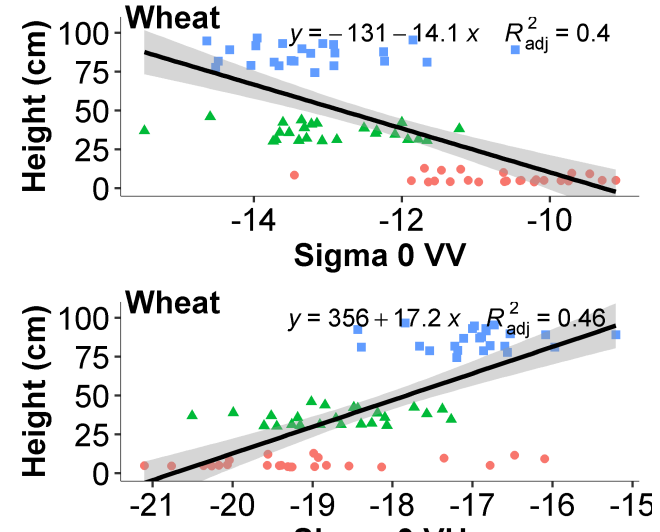

Sigma $0 \mathrm{VH}$
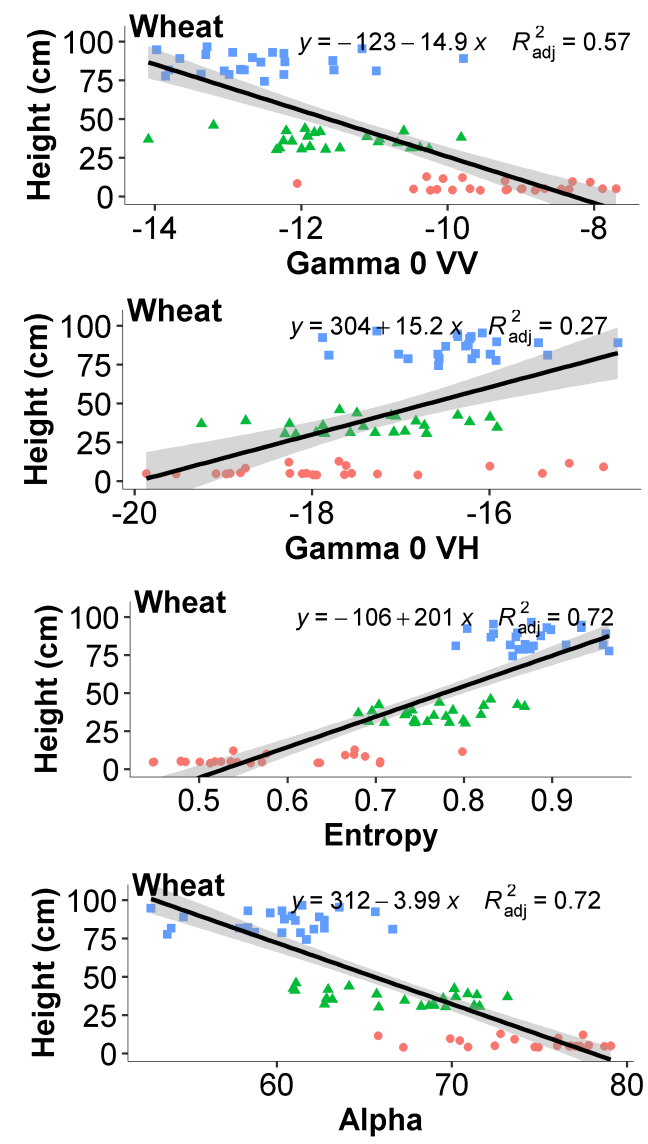

Legend

Height (cm):DAS 017

SAR:DAS 018

Height $(\mathrm{cm})$ :DAS 064

SAR:DAS 066

SAR:DAS DG6 101

Height (cm):DAS
SAR:DAS 095

Figure 7. Relationship between Height and Sigma, Gamma,

Entropy and Alpha angle for wheat.

The relationship among soybean LAI and polarimetric parameters is present in Figure 8. All the attributes presented $\mathrm{R}_{\text {adj }}^{2}$ lower than 0.32. Like showed in Figure 5, for soybean crop, the higher relation is between LAI and sigma crosspolarization backscattering. Figure 9 shows the scatter plots between SAR and LAI attributes for wheat. Gamma0 VH, sigma0 $\mathrm{VH}$ and entropy presented positive relations with LAI, while the other attributes had negative relations. The higher coefficients of determination were obtained for the entropy and alpha ( $\mathrm{R}^{2}$ of 0.62 and 0.56 , respectively).
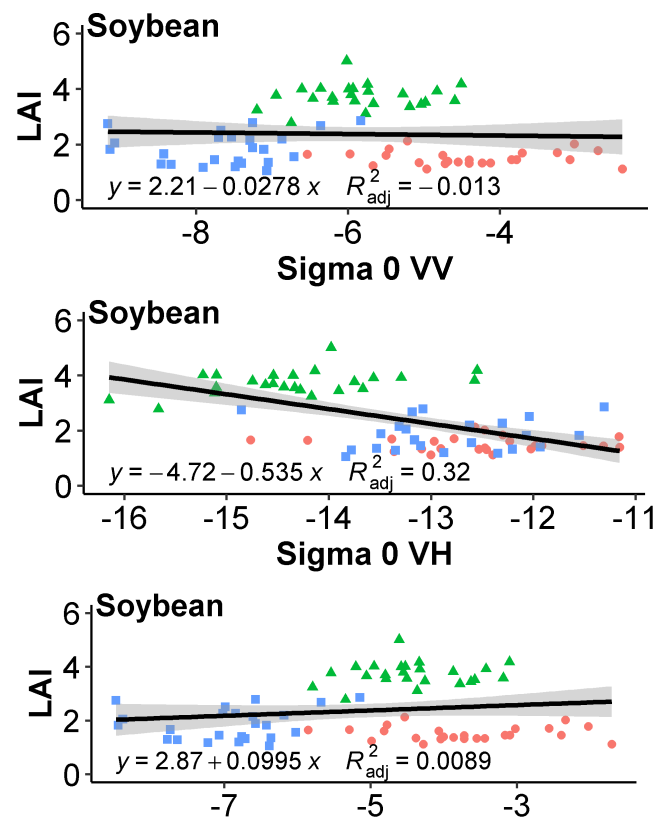

Gamma 0 VV
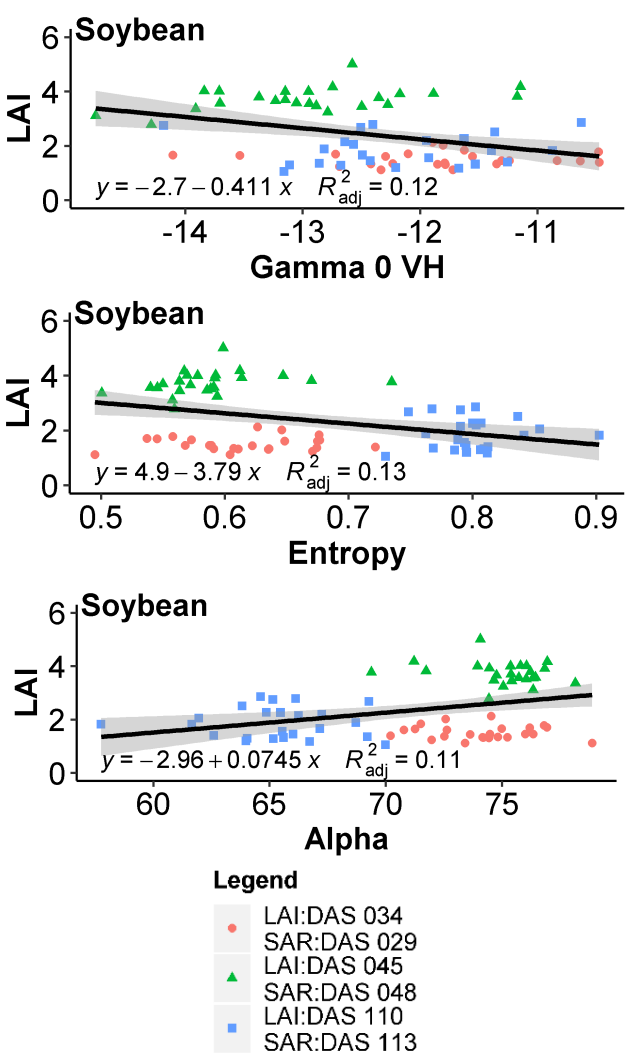

Figure 8. Relationship between LAI and Sigma, Gamma, Entropy and Alpha angle for soybean. 

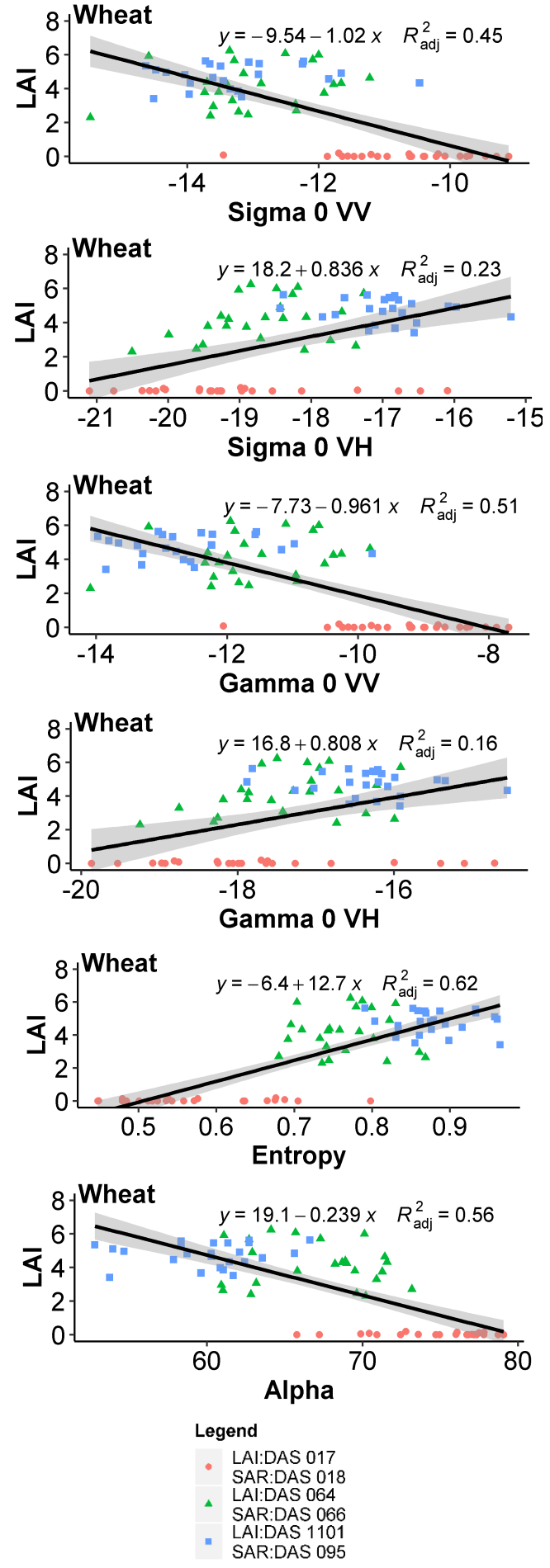

Figure 9. Relationship between LAI and Sigma, Gamma, Entropy and Alpha angle for wheat.

Figure 10 and 11 showed the relation between interferometric coherence and biophysical parameter to soybean and wheat respectively. Coherence did not show a relationship with any biophysical parameters. However, Tamm et al. (2016) found relation between coherence SAR/Sentinel-1 and grass height in three different places at Estonia. Their results showed that after a mowing event, median $\mathrm{VH}$ and VV polarization coherence values were statistically significantly higher than those from before the event.
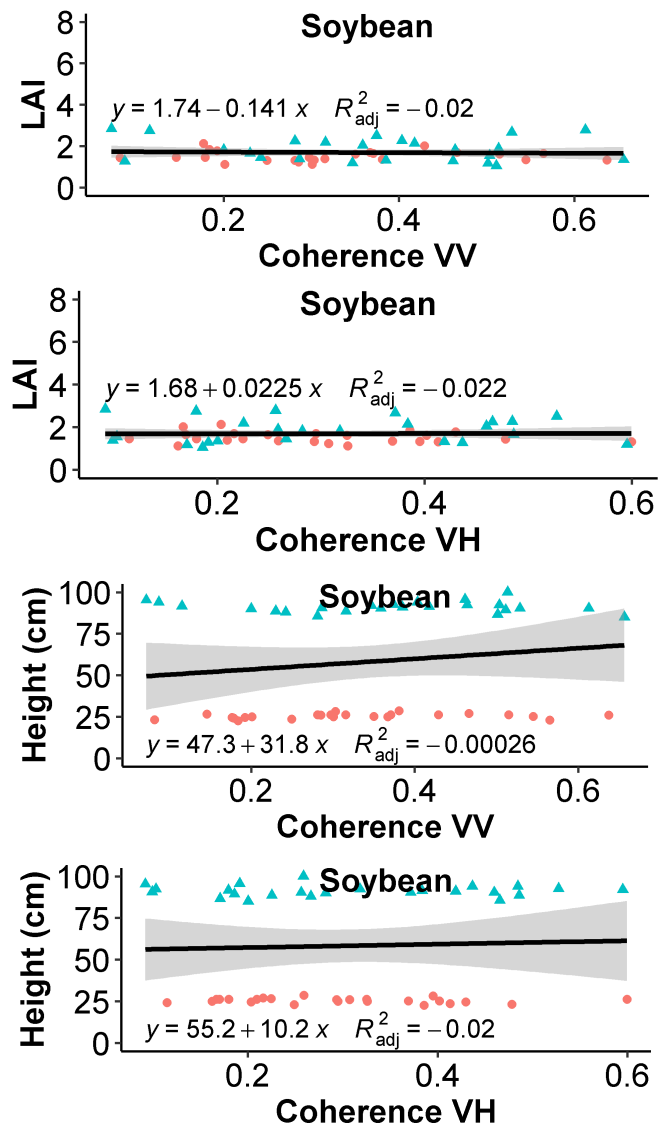

Legend

Field:DAS 034

SAR:DAS $24 / 48$

Field:DAS 110

SAR:DAS 96/120

Figure 10. Relationship between biophysical and coherence to soybean crop.

Co-polarized backscatter was inversely related with biophysical crop parameters. As the cultures devolved, the energy interacts more with the structure of the canopies and the co-polarization backscatter decreases. These occur due the energy interaction with the canopy, causes a signal depolarization, increasing the volumetric backscattering, cross polarization. This fact occurred for the height and for the LAI, being more evident for the wheat crop, where the measurements performed the period of greatest growth of the crops. Zhou et al. (2017) mentioned that with the gradual growth of wheat, the leaf density and the rod density gradually increased, and the wheat was more uniformly covered on the ground surface. The dominant position of the surface scattering decreased gradually, and the backscatter value decreased with the increase of the leaf density trend.

Coherence values were lower for all dates in both crops. This represents that there are differences between the analyzed images, probably due to the growth of the crops. However, due to the longer time interval between each image in each pair and between pairs, it was not possible to establish a pattern of the temporal behavior of interferometric coherence. 

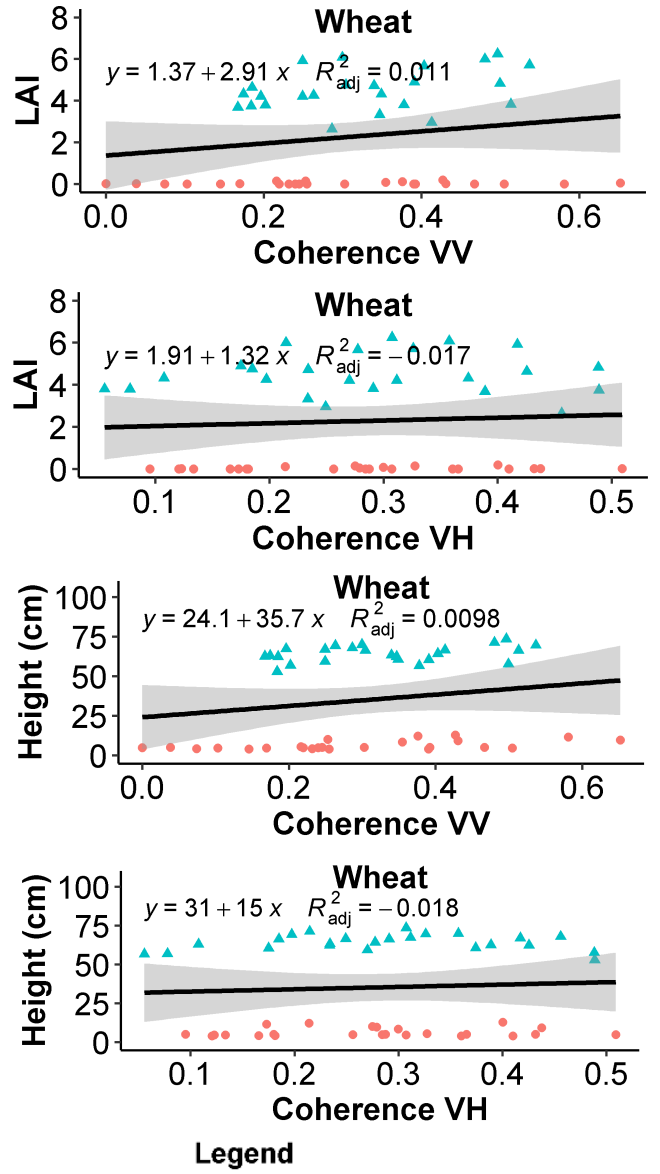

Field:DAS 017

SAR:DAS $-05 / 18$

Field:DAS 080

SAR:DAS $66 / 90$

Figure 11. Relationship between biophysical and coherence for wheat crop.

\section{CONCLUSIONS}

SAR polarimetric parameters are related with crops biophysical parameters and can be used as a source of information to monitor agricultural. However, the complexity of SAR data including its processing make it difficult to use this type of data.

In this study, interferometric coherence showed lower values, which suggests that the crops canopy changed between images. However, it is necessary more SAR images and more field data to establish a better relation between interferometry coherence and crop height. Interferometric technique needs a complex processing and work better with a full polarimetric SAR.

This preliminary study serves as a basis for future research with SAR/Sentinel-1 data focused on crops. We believe our results could be better if more SAR and field data were available.

\section{ACKNOWLEDGEMENTS}

This study was financed in part by the Coordenação de Aperfeiçoamento de Pessoal de Nível Superior - Brasil (CAPES) Finance Code 001 and the National Council for Scientific and Technological Development (CNPq). We thank the Agroindustrial
Cooperative of Cascavel (COOPAVEL) and Plantar Agrícola for making the monitored areas available for study and the RUS Copernicus team for the VM.

\section{REFERENCES}

Cloude, S.R., Pettier, E., 1996. A review of target decomposition theorems in radar polarimetry. IEEE Trans. Geosci. Remote Sens. 34, pp. 498-518. https://doi.org/10.1109/36.485127.

Erten, E., Lopez-Sanchez, J.M., Yuzugullu, O., Hajnsek, I., 2016. Retrieval of agricultural crop height from space: A comparison of SAR techniques. Remote Sens. Environ. 187, pp. 130-144. https://doi.org/10.1016/j.rse.2016.10.007.

ESA, E.S.A., 2013. Sentinel-1 User Handbook.

Ji, K., Wu, Y., 2015. Scattering mechanism extraction by a modified Cloude-Pottier decomposition for dual polarization SAR. Remote Sens. 7, pp. 7447-7470. https://doi.org/10.3390/rs70607447.

LI-COR, I., 2014. LAI - 2200C - Plant Canopy Analyzer. https://doi.org/10.1007/s13398-014-0173-7.2.

Liu, C., Shang, J., Vachon, P.W., McNairn, H., 2013. Multiyear Crop Monitoring Using Polarimetric RADARSAT-2 Data. IEEE Trans. Geosci. Remote Sens. 51, pp. 2227-2240. https://doi.org/10.1109/TGRS.2012.2208649.

López-Martínez, C., Lopez-Sanchez, J.M., 2017. Polarimetric SAR Techniques and Applications, 1st ed. MDPI AG, Basel.

McNairn, H., Champagne, C., Shang, J., Holmstrom, D., Reichert, G., 2009. Integration of optical and Synthetic Aperture Radar (SAR) imagery for delivering operational annual crop inventories. ISPRS J. Photogramm. Remote Sens. 64, pp. 434-449. https://doi.org/10.1016/j.isprsjprs.2008.07.006.

Mohammadimanesh, F., Salehi, B., Mahdianpari, M., Brisco, B., Motagh, M., 2018. Multi-temporal, multi-frequency, and multipolarization coherence and SAR backscatter analysis of wetlands. ISPRS J. Photogramm. Remote Sens. 142, pp. 78-93. https://doi.org/10.1016/j.isprsjprs.2018.05.009.

Palazzo, F., Šmejkalová, T., Castro-Gomez, M., Rémondière, S., Scarda, B., Bonneval, B., Gilles, C., Guzzonato, E., Mora, B., 2018. RUS: A New Expert Service for Sentinel Users. Proceedings 2, 369. https://doi.org/10.3390/ecrs-2-05183.

Parihar, N., Das, A., Rathore, V.S., Nathawat, M.S., Mohan, S., 2014. Analysis of L-band SAR backscatter and coherence for delineation of land-use/land-cover. Int. J. Remote Sens. 35, pp. 6781-6798. https://doi.org/10.1080/01431161.2014.965282.

Srivastava, H.S., Patel, P., Navalgund, R.R., 2006. Application potentials of synthetic aperture radar interferometry for land-cover mapping and crop-height estimation. Curr. Sci. 91, pp. 783-788.

Steele-Dunne, S.C., McNairn, H., Monsivais-Huertero, A., Judge, J., Liu, P.-W., Papathanassiou, K., 2017. Radar Remote Sensing of Agricultural Canopies: A Review. IEEE J. Sel. Top. Appl. Earth Obs. Remote Sens. 10, pp. 2249-2273. https://doi.org/10.1109/JSTARS.2016.2639043.

Tamm, T., Zalite, K., Voormansik, K., Talgre, L., 2016. Relating Sentinel-1 Interferometric Coherence to Mowing Events on Grasslands. Remote Sens. 8, 802. https://doi.org/10.3390/rs8100802.

Veloso, A., Mermoz, S., Bouvet, A., Le Toan, T., Planells, M., Dejoux, J.F., Ceschia, E., 2017. Understanding the temporal behavior of crops using Sentinel-1 and Sentinel-2-like data for agricultural applications. Remote Sens. Environ. 199, pp. 415-426. 
https://doi.org/10.1016/j.rse.2017.07.015.

Zheng, G., Moskal, L.M., 2009. Retrieving Leaf Area Index (LAI) Using Remote Sensing: Theories, Methods and Sensors. Sensors 9, pp. 2719-2745. https://doi.org/10.3390/s90402719.

Zhou, T., Pan, J., Zhang, P., Wei, S., Han, T., 2017. Mapping winter wheat with multi-temporal SAR and optical images in an urban agricultural region. Sensors (Switzerland) 17, pp. 1-16. https://doi.org/10.3390/s17061210. 